\title{
Interaction between Dietary and Lifestyle Risk Factors and N-Acetyltransferase Polymorphisms in B-Cell Lymphoma Etiology
}

Pierluigi Cocco ${ }^{*}$, Mariagrazia Zucca ${ }^{2}$, Sonia Sanna ${ }^{2}$, Giannina Satta ${ }^{1}$, Emanuele Angelucci ${ }^{3}$, Attilio Gabbas ${ }^{1}$, Maria Monne ${ }^{4}$, Marcello Campagna ${ }^{1}$, Aldo Scarpa ${ }^{5}$ and Maria Grazia Ennas ${ }^{2}$

${ }^{1}$ Department of Public Health, Clinical and Molecular Medicine, Occupational Health Section, University of Cagliari, Monserrato (Cagliari), 09042, Italy

${ }^{2}$ Department of Biomedical Sciences, Cytomorphology Section, University of Cagliari, Monserrato (Cagliari), 09042, Italy

${ }^{3}$ Unit of Haematology, A. Businco Oncology Hospital, Local Health Unit ASL 8, Cagliari, 09121, Italy

${ }^{4}$ Unit of Hematology, San Francesco Hospital, Local Health Unit ASL 3, 08100 Nuoro, Italy

${ }^{5}$ ARC-NET Research Centre and Department of Pathology and Diagnostics, University of Verona, 37134, Italy

\begin{abstract}
Background: Gene-environment interactions are suggested to play a role in lymphomagenesis.

Methods: We tested the interaction between the NAT1/NAT2 phenotype, as inferred by the respective genotypes, and exposure to dietary and lifestyle risk factors, in 199 incident lymphoma cases and 188 population controls. We used unconditional logistic regression to calculate the odds ratio (OR) and its $95 \%$ confidence interval for lymphoma (all subtypes combined) and B cell lymphoma, associated to the rapid NAT1 phenotype and to the intermediate and slow NAT2 phenotype, and to the estimated dietary intake of heterocyclic amines and folate, current smoking, coffee, and use of permanent hair dyes, as well as the respective interaction terms. We adjusted the ORs by age, gender, and education, and we used the likelihood ratio test to test the interaction between the NAT1, NAT2 phenotype and the dietary and lifestyle variables.
\end{abstract}

Results: We observed an increase in risk of lymphoma (all subtypes combined) and B-cell lymphoma in particular associated with the estimated above median dietary intake of heterocyclic amines (OR $=4.2,95 \% \mathrm{Cl} 1.2-14.8$ ) and folate $(\mathrm{OR}=4.1,95 \% \mathrm{Cl} 0.7-22.4)$ among subjects with the NAT1 rapid acetylator phenotype, but not independent on the NAT1 phenotype. The test for interaction was significant for heterocyclic amines, but not for folate ( $p$ for interaction $=0.026$ and 0.076 respectively). Ever use of permanent hair dyes was associated with an elevated risk independent on the NAT1, NAT2 phenotypes; risk decreased to null among intermediate and slow NAT1 acetylators ( $p$ for interaction $=$ 0.010).

Conclusions: Our results suggest that NAT1, NAT2 polymorphisms interact with dietary and lifestyle exposures in modulating risk of lymphoma and particularly B-cell lymphoma.

Keywords: Lymphomas; N-acetyl transferase; Molecular epidemiology; Gene-environment interaction; Smoking; Coffee; Folate; Heterocyclic amines

Abbreviations: CI: Confidence Interval; DLBCL: Diffuse Large B-Cell Lymphoma; FL: Follicular Lymphoma; HWE: Hardy-Weinberg Equilibrium; NAT1: N-Acetyl Transferase, Type 1; NAT2: N-Acetyl Transferase, Type 2; NHL: Non Hodgkin Lymphoma; OR: Odds Ratio; SES: Socio-Economic Status

\section{Introduction}

Typical substrates of the arylamine $\mathrm{N}$-acetyl transferase 1 and 2 (NAT1, NAT2) enzymes include aromatic amines, putative responsible for the excess of non Hodgkin lymphoma (NHL) risk associated with use of hair dyes [1,2]; heterocyclic amines, known animal carcinogens, found in overcooked red meat but also occurring in well done roasted chicken, salmon, and cigarette smoke condensate [3]; and folate [4,5], which is implicated in one-carbon transfer reactions for DNA synthesis and methylation [6]. Notably, all these agents have been investigated as possible NHL risk factors [1,2,4-12], and, although inconclusively, NAT1, NAT2 gene polymorphisms have also been related to risk of NHL and its major B-cell subtypes, namely diffuse large B-cell lymphoma (DLBCL), and follicular lymphoma (FL) [13-16]. It is plausible that specific nutrients and chemicals from environmental exposures and lifestyle habits might act as carcinogens, and/or they might interfere with epigenetic conditions in silencing or enhancing the expression of genes implicated in the mechanisms leading to the development of specific lymphoma subtypes. Therefore, we explored risk of lymphoma (all subtypes combined), and B-cell lymphoma associated with the genotype-based NAT1/NAT2 phenotypes and their interaction with dietary and lifestyle risk factors conveying exposure to typical NAT1, NAT2 substrates in a population-based case-control study.

\section{Methods}

Details on the study can be found elsewhere [16]. Briefly, in 19992003, adult incident cases with a diagnosis of lymphoma were recruited at the A. Businco Oncology Hospital in Cagliari, and the S. Francesco Hospital in Nuoro, two major referral centres for diagnosis and treatment of haematological malignancies in Sardinia, Italy. Population controls were randomly selected within the study area, frequency matched to cases by age (25-74 years by 5 -year age-groups), gender, and geographic area of residence. Study participants $(88 \%$ of eligible cases

*Corresponding author: Pierluigi Cocco, MD, Department of Public Health, Clinical and Molecular Medicine, Occupational Health Section, University of Cagliari, Asse Didattico E, ss 554, KM 4,500, 09042 Monserrato, Cagliari, Italy, Tel: 390706754711; Fax: 390706754728; E-mail: coccop@medicina.unica.it

Received July 29, 2015; Accepted August 14, 2015; Published August 17, 2015

Citation: Cocco P, Zucca M, Sanna S, Satta G, Angelucci E, et al. (2015) Interaction between Dietary and Lifestyle Risk Factors and N-Acetyltransferase Polymorphisms in B-Cell Lymphoma Etiology. J Environ Anal Toxicol 5: 315 doi:10.4172/2161-0525.1000315

Copyright: $\odot 2015$ Cocco $\mathrm{P}$, et al. This is an open-access article distributed under the terms of the Creative Commons Attribution License, which permits unrestricted use, distribution, and reproduction in any medium, provided the original author and source are credited. 
and $69.2 \%$ of eligible controls) underwent an in-person interview with a semi-structured questionnaire, including information on smoking, use of hair dyes and diet, and donated a $20 \mathrm{ml}$ blood sample. A DNA sample was available for $248 / 322$ participating lymphoma patients (77\%), and, 208/446 (47\%) population controls. For the purposes of this analysis, we focused on lymphoma (all subtypes combined) and on the B-cell lymphoma subgroup, as the study size was not sufficient to explore gene-environment interactions by histologically confirmed lymphoma subtype.

As previously described [16], we used multiplex PCR and allele specific primers to detect NAT1 $\left({ }^{\star} 4,{ }^{*} 10\right.$ and $\left.{ }^{\star} 11\right)$ and NAT2 $\left({ }^{\star} 5\right.$ A, ${ }^{\star} 5 \mathrm{~B},{ }^{\star} 5 \mathrm{C},{ }^{\star} 6$ and $\left.{ }^{\star} 7\right)$ haplotypes, as suggested by Smith et al. [17]. Laboratory technicians were blind to the case-control status. Duplicate samples from 50 cases and 100 controls were interspersed throughout the plates for concordance analysis, which rate was $100 \%$ for all assays. Hardy-Weinberg Equilibrium (HWE) was tested in controls using the $\chi^{2}$ Goodness-of-fit test: no HWE deviation was detected.

Based on functional information $[18,19]$, we categorized the NAT1 genotypes by the associated rapid (NAT1 ${ }^{*} 10 /{ }^{*} 10,{ }^{*} 4 /{ }^{*} 11$, ${ }^{\star} 10 /{ }^{\star} 11$ or ${ }^{\star} 11 /{ }^{\star} 11$ genotypes) or slow acetylator (NAT1 ${ }^{\star} 4 /{ }^{\star} 4$ or ${ }^{*} 4 /{ }^{*} 10$ genotypes) phenotype, and the NAT2 genotypes by the rapid (NAT2 ${ }^{*} 4 /{ }^{*} 4$ genotype), intermediate (NAT2 ${ }^{*} 4 /{ }^{*} 5,{ }^{*} 4 /{ }^{*} 6$, and ${ }^{*} 4 /{ }^{*} 7$ genotypes) and slow acetylator phenotype (NAT2 ${ }^{\star} 5 /{ }^{\star} 5,{ }^{\star} 5 /{ }^{\star} 6,{ }^{\star} 5 /{ }^{*} 7$, ${ }^{\star} 6 /{ }^{*} 6,{ }^{\star} 6 /{ }^{*} 7$ and ${ }^{*} 7 /{ }^{*} 7$ genotypes).

Using the questionnaire information, we categorized smoking as a binary variable (current smokers and ex smokers who quitted from $<5$ years $v s$ never smokers and ex smokers who quitted smoking $\geq 5$ years before interview). Coffee intake was highly prevalent in our study population, with $72 \%$ study subjects having coffee at least once a day; therefore, we categorized coffee intake as daily $v s$ less than daily. We used the frequency of intake of well done and very well done red meat and cooking method to define a score of dietary intake of heterocyclic amines; we tested score values above the median against below median values. Dietary folate intake was derived from the frequency of intake of 20 food items reported as its major sources [20]; we summed up the intake frequency of each individual item weighted by its reported average content in folate to build a score, which was subsequently categorized as a binary variable (above the median value $v s$ below median). Use of any permanent hair dye was considered to convey exposure to specific aromatic amines according to the type of colour [21], particularly before 1980 . To allow acceptable statistical power to this analysis, we only used the binary ever/never use of permanent hair dyes.

Odds ratios (OR) and 95\% confidence intervals (95\% CI) for lymphoma (all subtypes combined) and B-cell lymphoma associated with the rapid NAT1 phenotype and with the intermediate and slow NAT2 phenotype, the lifestyle risk factors as described above, and the respective interaction terms were estimated using unconditional logistic regression analysis, adjusting by age (continuous), gender and education. We used the likelihood ratio test [22] to formally test the interaction between the NAT1, NAT2 phenotype and the dietary and lifestyle variables we considered. Adjustment for the frequency matching factors was deemed necessary because of the varying acceptance rate of the biological part of the study protocol by age and gender. Education was used as a surrogate for socio-economic status (SES), and it was included as a covariate in the regression models to account for SES-related variation in the acceptance rate of the full study protocol, and in lifestyle habits, possibly conveying exposure to known lymphoma risk factors. All the analyses were performed with SPSS version 16.0 (SPSS Inc., Chicago, IL, USA).

The study protocol was approved by the Ethical Committee of the University Hospital of Cagliari, and by the Ethical Committee of the Local Health Unit N. 3, Nuoro. All study participants signed an informed consent form according to the Helsinki declaration.

\section{Results}

Table 1 shows selected characteristics of the study population. As a results of the lower acceptance rate of blood withdrawal among male controls, the gender distribution differed by case/control status $\left(\chi^{2}=3.71, p=0.054\right)$. All the dietary and lifestyle variables were approximately equally distributed by disease status, but ever use of hair dyes, which prevalence was approximately double among the cases in respect to the controls. The NAT1 haplotypes could not be determined for 49 cases and 20 controls, leaving 199 cases and 188 controls available for the analysis of the NAT1 interactions. The NAT2 haplotypes could not be determined for 54 cases and 23 controls, leaving 195 cases and 185 controls available for the analysis of the NAT2 interactions. Among study participants with available NAT1/NAT2 genotypes, the genotypes expressing the NAT1 rapid acetylator phenotype and those expressing the NAT2 slow acetylator phenotype were more represented among the cases.

Table 2 shows the results of the logistic regression model predicting risk of lymphoma (all subtypes combined) and B-cell lymphoma, associated with the dietary or lifestyle risk factor, the NAT1 phenotype, and the respective interaction term. Although, after adjusting for the NAT1 polimorphism, risk of lymphoma (all subtypes combined) and B-cell lymphoma associated with the estimated above median heterocyclic amines dietary intake was not elevated, risk significantly increased among subjects carrying the rapid NAT1 acetylator phenotype $(\mathrm{OR}=4.2,95 \%$ CI $1.2-14.5$; $p$ for interaction $=0.024$; and $\mathrm{OR}=4.2,95 \%$ CI $1.2-14.8 ; p$ for interaction $=0.026$, respectively). A dietary folate intake above the median was also associated with an elevated risk of lymphoma (all subtypes combined) $(\mathrm{OR}=3.8,95 \%$ CI 1.0 - 14.5), and B-cell lymphoma in particular $(\mathrm{OR}=4.1,95 \% \mathrm{CI}$ $0.7-22.4$ ), but no gene-environment interaction was detected ( $p=$ 0.094 and $p=0.076$, respectively). Risk of lymphoma, and particularly B-cell lymphoma, was significantly elevated among hair dye users independent on the NAT1 acetylator phenotype, while risk was null among hair dye users with the rapid NAT1 acetylator phenotype, although no interaction was detected. Current smoking and daily coffee intake did not show an independent association with risk of lymphoma (all subtypes combined) nor with risk of B-cell lymphoma, nor we saw evidence of an interaction with the NAT1 rapid acetylator phenotype.

Although with a very wide confidence interval, ever use of hair dyes was a strong independent predictor of risk of lymphoma (all subtypes combined) and of B-cell lymphoma, but risk was below unity among subjects with the intermediate and slow NAT2 acetylator phenotype ( $p$ for interaction $=0.005$, and $p=0.009$, respectively) (Table 3). In the models including the NAT2 polymorphism, smoking, coffee, heterocyclic amines, and folate did not show an independent association with risk of lymphoma (all subtypes combined) and B-cell lymphoma, nor we detected an interaction between these lifestyle and dietary risk factors and the NAT2 acetylator phenotype.

\section{Discussion}

We used functional data to infer the genotype-based NAT1/NAT2 acetylator phenotype, and questionnaire information to infer exposure to putative carcinogen substrates from diet and lifestyle habits. Our 
Citation: Cocco P, Zucca M, Sanna S, Satta G, Angelucci E, et al. (2015) Interaction between Dietary and Lifestyle Risk Factors and N-Acetyltransferase Polymorphisms in B-Cell Lymphoma Etiology. J Environ Anal Toxicol 5: 315. doi:10.4172/2161-0525.1000315

Page 3 of 5

\begin{tabular}{|c|c|c|c|}
\hline Covariate & Cases & Controls & Total \\
\hline \multicolumn{4}{|l|}{ Age, mean ( sd) } \\
\hline men & $55.7(13.8)$ & $58.1(13.0)$ & $56.8(13.5)$ \\
\hline women & $57.9(12.6)$ & $57.4(12.4)$ & $57.6(12.5)$ \\
\hline all & $56.5(13.4)$ & $57.8(12.7)$ & $57.1(13.0)$ \\
\hline \multicolumn{4}{|l|}{ Gender: $\mathrm{n}(\%)$} \\
\hline men & $121(60.8)$ & $96(51.1)$ & $217(56.1)$ \\
\hline women & $78(39.2)$ & $92(48.9)$ & $170(43.9)$ \\
\hline \multicolumn{4}{|l|}{ Education: $\mathrm{n}(\%)$} \\
\hline$<=$ middle school & $154(66.1)$ & $134(66.8)$ & $303(66.4)$ \\
\hline high school & $32(15.7)$ & $43(21.2)$ & $83(18.2)$ \\
\hline university & $12(5.6)$ & $11(5.8)$ & $26(5.7)$ \\
\hline missing & 1 & 0 & 1 \\
\hline \multicolumn{4}{|l|}{ NAT1 phenotype } \\
\hline slow & $155(77.9)$ & $170(90.4)$ & $325(84.0)$ \\
\hline rapid & $44(22.1)$ & $18(9.6)$ & $62(16.0)$ \\
\hline \multicolumn{4}{|l|}{ NAT2 phenotype } \\
\hline rapid & $11(5.7)$ & $46(24.9)$ & $57(15.0)$ \\
\hline intermediate & $79(40.7)$ & $79(42.7)$ & $158(41.7)$ \\
\hline slow & $104(53.6)$ & $60(32.4)$ & $164(43.3)$ \\
\hline missing & 5 & 3 & 8 \\
\hline \multicolumn{4}{|l|}{ Smoking } \\
\hline Never, ex smokers ( 5 years) & $140(70.4)$ & $138(73.4)$ & $278(71.8)$ \\
\hline Current, ex smokers $(<5$ years) & $59(29.6)$ & $50(26.6)$ & $109(28.2)$ \\
\hline \multicolumn{4}{|l|}{ Heterocyclic amines } \\
\hline Below median & $79(39.7)$ & $75(39.9)$ & $154(39.8)$ \\
\hline Above median & $120(60.3)$ & $113(60.1)$ & $233(60.2)$ \\
\hline \multicolumn{4}{|l|}{ Coffee } \\
\hline Less than daily & $55(27.6)$ & $53(28.2)$ & $108(27.9)$ \\
\hline Once a day or more & $144(72.4)$ & $135(71.8)$ & $279(72.1)$ \\
\hline \multicolumn{4}{|l|}{ Folate } \\
\hline Below median & $124(50.0)$ & $104(50.0)$ & $228(50.0)$ \\
\hline Above median & $124(50.0)$ & $104(50.0)$ & $228(50.0)$ \\
\hline \multicolumn{4}{|l|}{ Hair dyes } \\
\hline Never & $174(81.4)$ & $176(93.6)$ & $350(90.4)$ \\
\hline Ever & $25(12.6)$ & $12(6.4)$ & $37(9.6)$ \\
\hline
\end{tabular}

results suggest an interaction between above median dietary intake of heterocyclic amines and the NAT1 rapid acetylator phenotype in increasing risk of lymphoma and particularly B-cell lymphoma. We also observed that the NAT2 slow acetylator phenotype reduced to null the elevated risk of lymphoma, and B-cell lymphoma in particular, associated with use of hair dyes. Our findings are consistent with reports of an elevated non Hodgkin lymphoma (NHL) risk associated with intake of very well done red meat [7] and with use of permanent hair dyes [1,2], as well as with the hypothesis that polymorphisms in the genes involved in the metabolism of heterocyclic amines and aromatic amines, the putative carcinogens responsible for the associations we detected, modulate risk. On the other hand, we did not observe an interaction between the NAT1/NAT2 polymorphism with dietary folate intake, smoking and coffee. However, whether positive or null, our findings are purely tentative because of the small size and the limited statistical power of our study; therefore, the extreme variations in risk we observed should be interpreted cautiously.

As a consequence of the insufficient statistical power, we were unable to test the interactions by histological subtype. This is a further important limitation in our study, as substantial heterogeneity in risk factors has been described by lymphoma subtypes [23]. Nonetheless, our results prompt the need of further more powerful analyses, possibly using biomarkers of dose of the exposures of interest to reduce misclassification.

In conclusion, while our results seem intriguing in confirming the hypothesis of gene-environment interactions in the etiology of lymphoma and particularly B-cell lymphoma, caution is recommended in their interpretation, as further carefully planned, more powerful and more detailed studies are warranted.

\section{Acknowledgments}

Funding for this study was provided to PC by the Italian Ministry for Education, University and Research (PRIN 2007 prot.2007WEJLZB, PRIN 2009 prot 20092ZELR2), and the Italian Association for Cancer Research (AIRC, Investigator Grant 11855). Support to MGE was provided by Fondazione Banco di Sardegna 2010-2012, and Regione Autonoma della Sardegna (LR7 CRP-59812/2012) This study would have been impossible without the voluntary and disinterested contribution of all the patients and the population controls who accepted donating blood samples for the purposes of our study.

\section{Author contributions}

PC, MGE, and AS designed the study. M.Z, SS, GM, and MGE conducted the laboratory analyses. GS, TN, MC, and PC managed the data and conducted the

\begin{tabular}{|c|c|c|c|c|c|}
\hline & \multicolumn{2}{|l|}{ External risk factor } & \multirow{2}{*}{$\begin{array}{l}\text { NAT1 acetylator } \\
\text { phenotype } \\
\text { rapid vs slow } \\
\text { OR } \quad(95 \% \mathrm{Cl})\end{array}$} & \multirow{2}{*}{$\begin{array}{l}\text { Interactive term } \\
\text { OR } \quad(95 \% \mathrm{Cl})\end{array}$} & \multirow{2}{*}{$\begin{array}{l}\text { Likelihood ratio test, } \\
\text { df ( } p \text { value) }\end{array}$} \\
\hline & Categories & OR $\quad(95 \% \mathrm{Cl}))$ & & & \\
\hline \multicolumn{6}{|l|}{ All lymphomas combined } \\
\hline Model 1. Smoking & Current smokers vs never + ex-smokers & $1.2(0.7-1.9)$ & $3.3(1.6-7.1)$ & $0.6 \quad(0.2-2.1)$ & $0.63,1,0.427$ \\
\hline Model 2. Coffee & Daily vs less than daily & $1.2(0.7-2.0)$ & $4.3(1.3-14.8)$ & $0.6 \quad(0.1-2.3)$ & $0.67,1,0.411$ \\
\hline Model 3. Heterocyclic amines & >median vs <median & $0.8 \quad(0.5-1.2)$ & $1.2(0.5-3.1)$ & $4.2(1.2-14.5)$ & $5.08,1,0.024$ \\
\hline Model 4. Folate & $>$ median vs < median & $1.1 \quad(0.7-1.9)$ & $2.1 \quad(1.1-4.2)$ & $3.8(1.0-14.5)$ & $2.80,1,0.094$ \\
\hline Model 5. Hair dyes & Ever use vs never & $4.4 \quad(1.9-10.3)$ & $3.4 \quad(1.8-6.5)$ & $0.2 \quad(0.02-6.4)$ & $2.35,1,0.125$ \\
\hline \multicolumn{6}{|l|}{ B-cell lymphoma } \\
\hline Model 1. Smoking & Current smokers vs never + ex-smokers & $1.2(0.7-2.0)$ & $3.8 \quad(1.8-8.2)$ & $0.6 \quad(0.2-2.0)$ & $0.75,1,0.388$ \\
\hline Model 2. Coffee & Daily vs less than daily & $1.2 \quad(0.7-2.0)$ & $5.3(1.5-18.3)$ & $0.5 \quad(0.1-2.1)$ & $0.97,1,0.325$ \\
\hline Model 3. Heterocyclic amines & $>$ median vs <median & $0.8 \quad(0.5-1.2)$ & $1.4 \quad(0.6-3.5)$ & $4.2(1.2-14.8)$ & $4.99,1,0.026$ \\
\hline Model 4. Folate & >median vs <median & $1.0 \quad(0.6-1.7)$ & $2.3(1.2-4.7)$ & $4.1 \quad(0.7-22.4)$ & $3.14,1,0.076$ \\
\hline Model 5. Hair dyes & Ever use vs never & $4.9 \quad(2.1-11.8)$ & $3.9(2.0-7.5)$ & $0.2 \quad(0.02-1.3)$ & $2.63,1,0.105$ \\
\hline
\end{tabular}

Table 2: Risk of lymphoma (all subtypes combined) and B-cell lymphoma associated with dietary and lifestyle risk factors, the NAT1 rapid acetylator phenotype, and the respective interactions in Sardinia, Italy. ORs are adjusted by age (continuous), gender, and education. 
Citation: Cocco P, Zucca M, Sanna S, Satta G, Angelucci E, et al. (2015) Interaction between Dietary and Lifestyle Risk Factors and N-Acetyltransferase Polymorphisms in B-Cell Lymphoma Etiology. J Environ Anal Toxicol 5: 315. doi:10.4172/2161-0525.1000315

Page 4 of 5

\begin{tabular}{|c|c|c|c|c|c|c|}
\hline & \multicolumn{3}{|c|}{ External risk factor } & \multirow{2}{*}{$\begin{array}{l}\text { NAT2 acetylator phenotype } \\
\text { intermediate vs rapid } \\
\text { OR }(95 \% \mathrm{Cl})\end{array}$} & \multirow{2}{*}{\begin{tabular}{|c|} 
NAT2 acetylator phenotype \\
intermediate vs rapid \\
OR $(95 \% \mathrm{Cl})$
\end{tabular}} & \multirow{2}{*}{\begin{tabular}{|c|}
$\begin{array}{c}\text { Likelihood ratio } \\
\text { test, }\end{array}$ \\
$\mathrm{df}(\mathrm{p}$ value $)$
\end{tabular}} \\
\hline & Categories & OR & $(95 \% \mathrm{Cl}))$ & & & \\
\hline \multicolumn{7}{|l|}{ All lymphomas combined } \\
\hline Model 1. Smoking & $\begin{array}{l}\text { Current smokers vs never + ex } \\
\text { smokers }\end{array}$ & 1.9 & $(0.4-8.1)$ & $5.0 \quad(2.0-12.2)$ & $9.3 \quad(3.8-22.9)$ & \multirow[t]{2}{*}{$1.52,2,0.468$} \\
\hline Model 1: interaction terms & & & & $0.6 \quad(0.1-3.1)$ & $0.4 \quad(0.1-2.0)$ & \\
\hline Model 2. Coffee & Daily vs less than daily & 0.4 & $(0.1-1.4)$ & $2.8(0.9-8.8)$ & $2.9 \quad(0.9-9.1)$ & \multirow[t]{2}{*}{$3,82,2,0.148$} \\
\hline Model 2: interaction terms & & & & $2.3 \quad(0.5-10.6)$ & $4.2 \quad(0.9-19.6)$ & \\
\hline Model 3. Heterocyclic amines & $>$ median vs <median & 0.8 & $(0.2-3.1)$ & $4.4 \quad(1.5-13.2)$ & $6.9 \quad(2.2-21.6)$ & \multirow[t]{2}{*}{$0.06,2,0.970$} \\
\hline Model 3: interaction terms & & & & $1.1 \quad(0.2-4.9)$ & $1.0(0.2-4.9)$ & \\
\hline Model 4. Folate & >median vs <median & 0.4 & $(0.1-2.0)$ & $3.1 \quad(1.4-7.1)$ & $5.1 \quad(2.2-11.7)$ & \multirow[t]{2}{*}{$2.48,2,0.289$} \\
\hline Model 4: interaction terms & & & & $3.8 \quad(0.6-23.6)$ & $3.7 \quad(0.6-22.6)$ & \\
\hline Model 5. Hair dyes & Ever use vs never & 25.5 & $(2.2-293)$ & $5.1 \quad(2.2-11.7)$ & $10.2 \quad(4.4-23.6)$ & \multirow[t]{2}{*}{$10.31,2,0.006$} \\
\hline Model 5: interaction terms & & & & $0.3 \quad(0.02-5.4)$ & $0.04 \quad(0.03-0.5)$ & \\
\hline \multicolumn{7}{|l|}{ B-cell lymphoma } \\
\hline Model 1. Smoking & $\begin{array}{l}\text { Current smokers vs never + ex- } \\
\text { smokers }\end{array}$ & 1.6 & $(0.3-7.5)$ & $4.7 \quad(1.9-11.5)$ & $8.3 \quad(3.4-20.7)$ & \multirow[t]{2}{*}{$1.59,2,0.452$} \\
\hline Model 1: interaction terms & & & & $0.8 \quad(0.1-4.5)$ & $0.5 \quad(0.1-2.5)$ & \\
\hline Model 2. Coffee & Daily vs less than daily & 0.4 & $(0.1-1.8)$ & $3.3 \quad(1.0-10.9)$ & $3.2(1.0-10.5)$ & \multirow[t]{2}{*}{$2.71,2,0.258$} \\
\hline Model 2: interaction terms & & & & $1.8(0.4-8.7)$ & $3.3(0.7-16.0)$ & \\
\hline Model 3. Heterocyclic amines & $>$ median vs <median & 0.7 & $(0.2-2.7)$ & $4.1 \quad(1.4-12.2)$ & $6.0 \quad(1.9-19.1)$ & \multirow[t]{2}{*}{$0.09,2,0.956$} \\
\hline Model 3: interaction terms & & & & $1.2(0.3-5.6)$ & $1.3(0.3-6.0)$ & \\
\hline Model 4. Folate & $>$ median vs < median & 0.2 & $(0.02-1.7)$ & $2.9 \quad(1.3-6.7)$ & $4.5 \quad(2.0-10.5)$ & \multirow[t]{2}{*}{$4.25,2,0.119$} \\
\hline Model 4: interaction terms & & & & $7.9 \quad(0.8-79.0)$ & $6.3 \quad(0.6-63.0)$ & \\
\hline Model 5. Hair dyes & Ever use vs never & 29.9 & $(2.6-349)$ & $5.5 \quad(2.3-13.2)$ & $9.8 \quad(4.0-23.6)$ & \multirow[t]{2}{*}{$9.23,2,0.010$} \\
\hline Model 5: interaction terms & & & & $0.3 \quad(0.02-4.3)$ & $0.04(0.003-0.6)$ & \\
\hline
\end{tabular}

Table 3: Risk of lymphoma (all subtypes combined) and B-cell lymphoma associated with NAT2 acetylator phenotypes, as inferred from the respective haplotype-based genotypes, in Sardinia, Italy. ORs are adjusted by age (continuous), gender, and education.

epidemiological analysis. PC, MZ, SS, EA, AG, MR, MC, AS, and MGE wrote and reviewed the manuscript. All authors made significant contributions to, reviewed, and approved the final version of the manuscript

\section{Conflict-of-interest}

All the authors declare no conflict of interest.

\section{References}

1. de Sanjosé S, Benavente Y, Nieters A, Foretova L, Maynadié M, et al. (2006) Association between personal use of hair dyes and lymphoid neoplasms in Europe. Am J Epidemiol 164: 47-55.

2. Morton LM, Bernstein L, Wang SS, Hein DW, Rothman N, et al. (2007) Hair dye use, genetic variation in N-acetyltransferase 1 (NAT1) and 2 (NAT2), and risk of non-Hodgkin lymphoma. Carcinogenesis 28: 1759-1764.

3. IARC Monographs on the Evaluation of the Carcinogenic Risk to Humans (1993) Some Naturally Occurring Substances: Food Items and Constituents, Heterocyclic Aromatic Amines and Mycotoxins (Volume 56) International Agency for Research on Cancer, Lyon.

4. Hein DW, Doll MA, Fretland AJ, Leff MA, Webb SJ, et al. (2000) Molecular genetics and epidemiology of the NAT1 and NAT2 acetylation polymorphisms. Cancer Epidemiol Biomarkers Prev 9: 29-42.

5. Cao W, Strnatka D, McQueen CA, Hunter RJ, Erickson RP (2010) $\mathrm{N}$-acetyltransferase 2 activity and folate levels. Life Sci 86: 103-106.

6. Choi SW, Mason JB (2000) Folate and carcinogenesis: an integrated scheme J Nutr 130: 129-132.

7. Cross AJ, Ward MH, Schenk M, Kulldorff M, Cozen W, et al. (2006) Meat and meat-mutagen intake and risk of non-Hodgkin lymphoma: results from a $\mathrm{NCl}$ SEER case-control study. Carcinogenesis 27: 293-297.

8. Moore T, Brennan P, Becker N, de Sanjosé S, Maynadié M, et al. (2007) Occupational exposure to meat and risk of lymphoma: a multicenter casecontrol study from Europe. Int J Cancer 121: 2761-2766.

9. Besson H, Brennan P, Becker N, Nieters A, De Sanjosé S, et al. (2006) Tobacco smoking, alcohol drinking and non-Hodgkin's lymphoma: an European multi- centre case-control study (Epilymph). Int J Cancer 119: 901-908.

10. Weiner AS, Beresina OV, Voronina EN, Voropaeva EN, Boyarskih UA, et al (2011) Polymorphisms in folate-metabolizing genes and risk of non-Hodgkin's lymphoma. Leuk Res 35: 508-515.

11. Lim U, Wang SS, Hartge P, Cozen W, Kelemen LE, et al. (2007) Gene-nutrient interactions among determinants of folate and one-carbon metabolism on the risk of non-Hodgkin lymphoma: NCI-SEER case-control study. Blood 109 3050-3059.

12. Lim U, Schenk M, Kelemen LE, Davis S, Cozen W, et al. (2005) Dietary determinants of one-carbon metabolism and the risk of non-Hodgkin's lymphoma: NCI-SEER case-control study, 1998-2000. Am J Epidemiol 162: 953-964.

13. Morton LM, Schenk M, Hein DW, Davis S, Zahm SH, et al. (2006) Genetic variation in N-acetyltransferase 1 (NAT1) and 2 (NAT2) and risk of non-Hodgkin lymphoma. Pharmacogenet Genomics 16: 537-545.

14. Gra OA, Glotov AS, Nikitin EA, Glotov OS, Kuznetsova VE, et al. (2008) Polymorphisms in xenobiotic-metabolizing genes and the risk of chronic lymphocytic leukemia and non-Hodgkin's lymphoma in adult Russian patients. Am J Hematol 83: 279-287.

15. Gibson TM, Smedby KE, Skibola CF, Hein DW, Slager SL, et al. (2013) Smoking, variation in N-acetyltransferase 1 (NAT1) and 2 (NAT2), and risk of non-Hodgkin lymphoma: a pooled analysis within the InterLymph consortium. Cancer Causes Control 24: 125-134.

16. Cocco P, Zucca M, Sanna S, Satta G, Nonne T, et al. (2015) N-acetyltransferase polymorphisms are associated with risk of lymphoma subtypes. Hematol Oncol.

17. Smith CA, Wadelius M, Gough AC, Harrison DJ, Wolf CR, et al. (1997) A simplified assay for the arylamine $\mathrm{N}$-acetyltransferase 2 polymorphism validated by phenotyping with isoniazid. J Med Genet 34: 758-760.

18. Wang D, Para MF, Koletar SL, Sadee W (2011) Human N-acetyltransferase *10 and *11 alleles increase protein expression through distinct mechanisms and associate with sulfamethoxazole-induced hypersensitivity. Pharmacogenet Genomics 21: 652-664. 
Citation: Cocco P, Zucca M, Sanna S, Satta G, Angelucci E, et al. (2015) Interaction between Dietary and Lifestyle Risk Factors and N-Acetyltransferase Polymorphisms in B-Cell Lymphoma Etiology. J Environ Anal Toxicol 5: 315. doi:10.4172/2161-0525.1000315

Page 5 of 5

19. Zang Y, Doll MA, Zhao S, States JC, Hein DW (2007) Functional characterization of single-nucleotide polymorphisms and haplotypes of human $\mathrm{N}$-acetyltransferase 2. Carcinogenesis 28: 1665-1671.

20. European Oncology Institute. Data base of food nutrients for epidemiological studies in Italy.

21. Munshi S (2004) Hair coloring products: colloid and surface phenomena.
22. Breslow NE, Day NE (1980) Statistical methods in cancer research. Volume I - The analysis of case-control studies. IARC Sci Publ : 5-338.

23. Morton LM, Slager SL, Cerhan JR, Wang SS, Vajdic CM, et al. (2014) Etiologic heterogeneity among non-Hodgkin lymphoma subtypes: the InterLymph NonHodgkin Lymphoma Subtypes Project. J Natl Cancer Inst Monogr 2014: 130144 